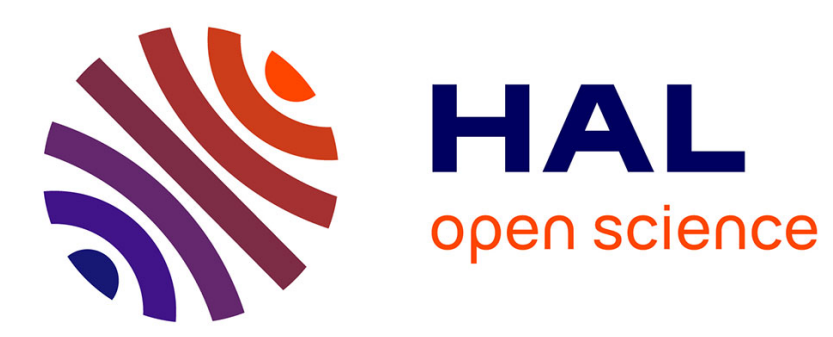

\title{
Investigating brittle failures in multiple-nail steel-to-timber connections
}

Anna Dupleix, Pierre Quenneville

\section{To cite this version:}

Anna Dupleix, Pierre Quenneville. Investigating brittle failures in multiple-nail steel-to-timber connections. Australian Journal of Civil Engineering, 2012, 10 (2), 10.7158/C11-695.2012.10.2 . hal01393719

\section{HAL Id: hal-01393719 \\ https://hal.science/hal-01393719}

Submitted on 8 Nov 2016

HAL is a multi-disciplinary open access archive for the deposit and dissemination of scientific research documents, whether they are published or not. The documents may come from teaching and research institutions in France or abroad, or from public or private research centers.
L'archive ouverte pluridisciplinaire $\mathbf{H A L}$, est destinée au dépôt et à la diffusion de documents scientifiques de niveau recherche, publiés ou non, émanant des établissements d'enseignement et de recherche français ou étrangers, des laboratoires publics ou privés. 


\title{
Investigating brittle failures in multiple-nail steel-to-timber connections
}

\author{
A Dupleix ${ }^{\dagger}$ and P Quenneville \\ Civil Engineering Department, University of Auckland, New Zealand
}

\begin{abstract}
Brittle failures should be avoided in timber structures because they engender unpredictable collapse in case of cyclic plastic deformations such as during earthquakes. In such cases, ductile failures should be promoted as they allow a redistribution of the load, enabling the building to remain standing. Intrinsically, wood is a brittle material. Ductility can be achieved in timber structures through connections using mechanical fasteners made out of steel. This study contributes by investigating the modes of failure of multiple-nail steel-to-timber connections loaded parallel to the grain in case of New Zealand Radiata Pine solid timber.
\end{abstract}

KEYWORDS: Embedding strength; timber structures; brittle failure; ductile failure; European Yield model; loadcarrying capacity; plug-shear failure; timber connections; multiple-nail steel-to-timber connections; Radiata Pine.

\section{NOTATION}

$a_{1} \quad$ spacing parallel to the grain, ie. spacing between fasteners within one row parallel to the grain of the timber member $(\mathrm{mm})$

$a_{2}$ spacing perpendicular to the grain, ie. spacing between fasteners within one row perpendicular to the grain of the timber member ( $\mathrm{mm}$ )

$a_{3, t} \quad$ distance of the fasteners to the loaded end of the timber member $(\mathrm{mm})$

$a_{4} \quad$ distance of the fasteners to the edge of the timber member (mm)

$b \quad$ width of the connection ( $\mathrm{mm}$ )

d fastener diameter ( $\mathrm{mm}$ )

E modulus of elasticity of timber $\left(\mathrm{kN} / \mathrm{mm}^{2}\right)$

$f_{h} \quad$ embedding strength in the timber member $\left(\mathrm{kN} / \mathrm{mm}^{2}\right)$ $f_{u} \quad$ tensile strength of the wire of the steel of the nail $\left(\mathrm{N} / \mathrm{mm}^{2}\right)$

$f_{y} \quad$ yield strength of the steel plate $\left(\mathrm{kN} / \mathrm{mm}^{2}\right)$

$F_{a x, R} \quad$ withdrawal capacity of the fastener $(\mathrm{kN})$

$F_{v, R} \quad$ load-carrying capacity of the connection per shear plane per fastener $(\mathrm{kN})$

$H \quad$ cross-sectional height of the timber member (mm)

$H^{\prime} \quad$ apparent cross-sectional height of the timber member $(\mathrm{mm})$

$k$ product of modification factors (no dimension)

$k_{e f} \quad$ modification factor on the number of fasteners per row (no dimension)

$l_{\text {nail }} \quad$ length of the nail ( $\mathrm{mm}$ )

MC moisture content of timber (\%)

$M_{y} \quad$ fastener yield moment (Nmm)

$m$ number of rows parallel to the grain of the timber member (no dimension)

$N \quad$ number of nails per connection (no dimension)

$n \quad$ number of fasteners in a row (no dimension) 
penetration depth of the fastener; also known as penetrated thickness of the timber $t(\mathrm{~mm})$

$p_{e f} \quad$ effective penetration depth of the fastener; also known as effective penetrated thickness of the timber $t_{e f}(\mathrm{~mm})$

$Q \quad$ strength of the connection $(\mathrm{kN})$

$Q_{n} \quad$ nominal strength of the connection $(\mathrm{kN})$

$R_{\text {ductile }}$ capacity resistance to ductile failure of multiple-nail steel-to-timber connection loaded parallel to the grain $(\mathrm{kN})$

$R_{\text {plug }}$ capacity resistance to brittle failure of multiplenail steel-to-timber connection loaded parallel to the grain $(\mathrm{kN})$

$t$ penetrated thickness of the timber; also known as penetration depth of the fastener $p(\mathrm{~mm})$

$t_{e f} \quad$ effective penetrated thickness of the timber; also known as effective penetration depth of the fastener $p_{e f}(\mathrm{~mm})$

$\lambda \quad$ slenderness ratio (no dimension)

$\rho \quad$ density of timber $\left(\mathrm{kg} / \mathrm{mm}^{3}\right)$

\section{INTRODUCTION}

The mode of failure of multiple-nail connections can be either brittle or ductile (or a combination of both). It depends on the way cracks propagate through the material, which is directly linked to the ability of the material to experience plastic deformation or not. During a plastic deformation, the material experiences an irreversible change in dimensions. The inner structure of the material is permanently modified and once the load is removed, the material remains in its deformed state. A plastic deformation differs therefore from an elastic deformation where the displacement is proportional to the amount of applied load.

A brittle material shows hardly no plastic deformation before failure. As soon as the crack is formed around a concentration of overstress, it is unstable. The crack spreads rapidly and continues to grow without any necessary further increase in the applied stress. Brittle

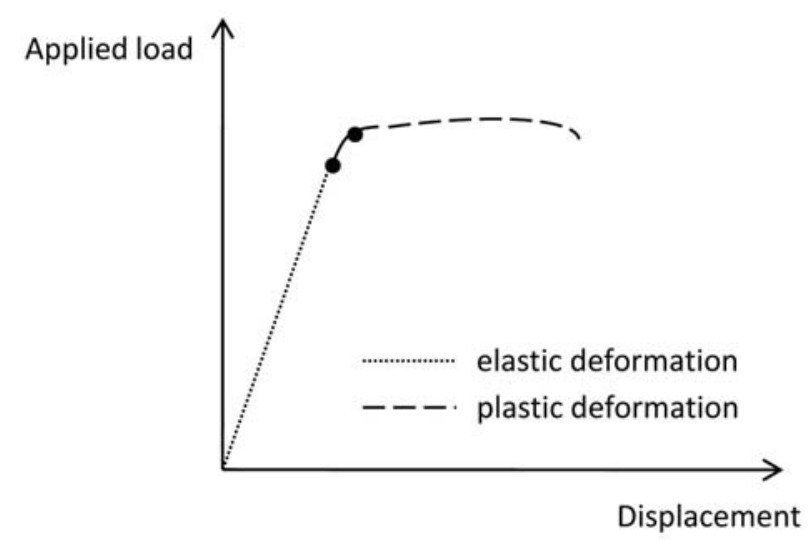

Figure 1: Schematic load-displacement curve of elastic and plastic deformations. failures lead therefore to a complete and sudden collapse of the structure. On the other hand, a ductile failure is a slower process. Cracks form around the concentration of stress but do not propagate because the fibres of the material around the crack deform plastically. During these plastic deformations, the ductile material absorbs energy and redistributes the overstressing loads. The cracks are stable and the failure will happen only when the fibres have reached their maximum of plastic deformation and could not retain the cracks from propagating. Ductile failures allow therefore the building to remain standing while the structure undergoes a plastic deformation which retains the cracks from propagating.

These statements clearly exhibit the importance of designing connections which will preferably lead to ductile failures than to brittle failures. Intrinsically, wood is a brittle material while steel is more ductile, showing a longer plastic response. Ductility in timber structures will be thus achieved through connections using mechanical fasteners made out of steel.

A ductile failure is characterised by the yielding of the nails which deform plastically by the embedment of the nails into the timber member or by forming plastic hinges (figure 5). Nails especially are often considered as ductile fasteners because they can deform plastically by forming plastic hinges. However, a recent doctoral thesis, concluded on the

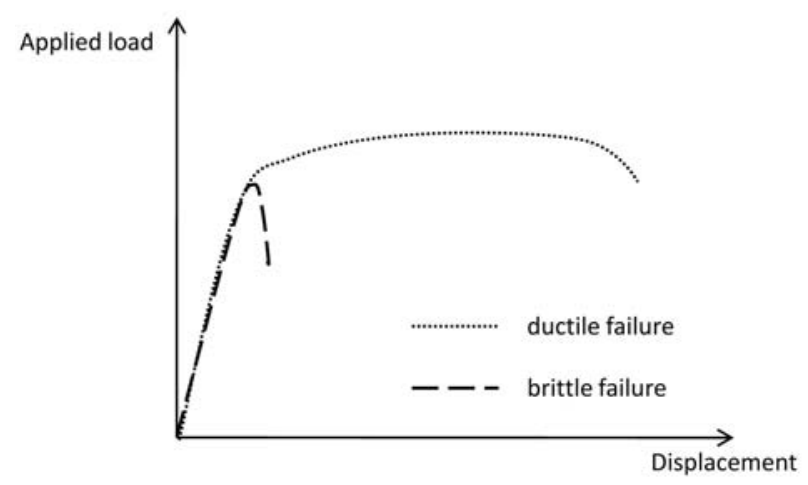

Figure 2: Schematic load-displacement curves for brittle and ductile materials loaded to failure.

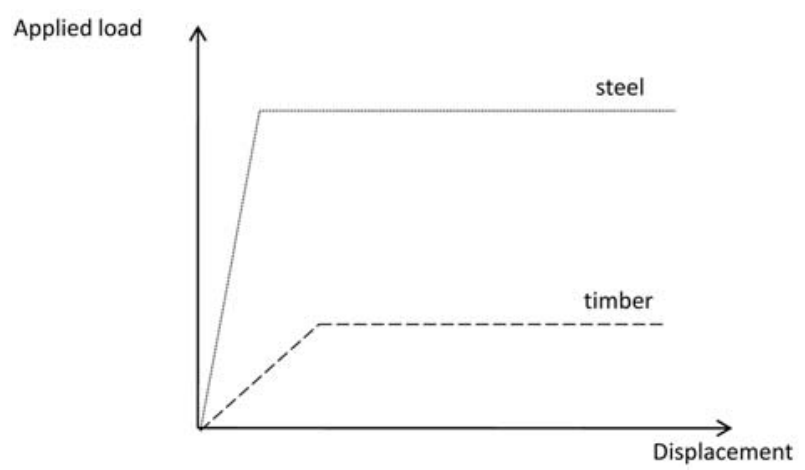

Figure 3: Schematic assumed loaddisplacement curves for steel and timber (Madsen, 2001). 
risk of brittle failures to happen also with multiplenail connections (Johnsson, 2004).

Brittle failures in timber connections were already in the spotlight of timber research needs, especially since 2003 when the collapse of a roof structure in Jyväskylä, Finland, was found to be due to a brittle mode of failure. Brittle modes of failure have been described in multiple fastener connections (Quenneville \& Morris, 2009). Brittle failures occur when timber is torn out of the rest of the member. A brittle failure is known as a row-shear failure if each row of nails is torn out independently (figure 4(a)) and as a block-shear or a plug-shear failure if the whole connection is involved (figure 4(b)). A blockshear failure penetrates entirely the timber member while there is only partial penetration of the timber member in a plug-shear failure (figures 4(b) and 4(c)).

Presently, the New Zealand Standard on Timber Structures NZS3603 (Standards New Zealand, 1993) and the European Eurocode 5 Standard of Design of Timber Structures (EC5) (CEN, 2004) only consider the case of ductile modes of failure. It is today of high interest to understand the mechanisms which lead to brittle failures in order to design timber connections which avoid them. The present study investigates the risk of brittle failures to occur in multiple-nail steel-to-timber connections made with New Zealand Radiata Pine solid timber. The aim is to propose to the New Zealand standard and the engineers predicting equations on the load-carrying capacity of New Zealand Radiata Pine solid timber taking into account the risk of brittle modes of failure to happen in multiple-nail connections.

\section{PREDICTION MODELS FOR DUCTILE FAILURES}

\subsection{The New Zealand Standard NZS3603}

The New Zealand Standard NZS3603 (Standards New Zealand, 1993) proposes the following equation to evaluate the strength of a multiple-nail steel-totimber connection $Q_{n}$ subjected to lateral loading:

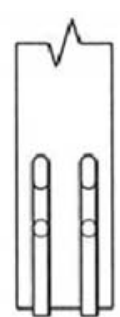

(a)

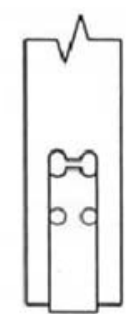

(b)

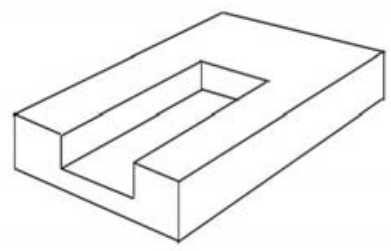

(c)
Figure 4: (a) Row-shear failure, (b) block-shear / plug-shear failure, and (c) plug-shear failure (Johnsson, 2004; Quenneville \& Morris, 2009).
$Q_{n}=N k Q$

where $N$ is the number of fasteners; $k$ is a product of modification factors such as the duration of loading, the steel plate thickness and the number of nails; and $Q$ is the strength of the connection tabulated according to the nails diameter and the timber species.

\subsection{The European Eurocode 5 Standard}

The EC5's (CEN, 2004) equations are derived from the European Yield Model, which assumes a perfect plastic behaviour between the steel of the fasteners and the surrounding timber (Johansen, 1949). The fasteners are modelled as beams where plastic hinges could form ( 0 plastic hinge in mode I, 1 plastic hinge in mode II and 2 plastic hinges in mode III). In each mode, the corresponding effective thickness of the timber $t_{e f^{\prime}}$ which plays a role in the resistance of the connection, is derived using Johansen's equations (equation (2), figure 5). The load-carrying capacity of the connection $F_{v, R}$ is derived from the first mode of deformation to occur in the fasteners (equation (2)).

$F_{v, R}=\min \left(f_{h} d t_{e f}\right)$

where in mode I, $t_{e f}=t$; mode II, $t_{e f}=t \sqrt{2+\frac{4 M_{y}}{f_{h} d t^{2}}-1}$;

and mode III, $t_{e f}=2 \sqrt{\frac{M_{y}}{f_{h} d}}$.

To account for the multiplicity of fasteners in the connection, the EC5 introduces the modification factor $k_{\text {ef }}$ on the number of fasteners per row. The load-carrying capacities of the multiple-nail steel-totimber connections $R_{\text {ductile }}$ are predicted according to equation (3) (ignoring the characteristic withdrawal capacity of the nail $F_{a x, R}$ considered as negligible in front of the first terms of the equations).
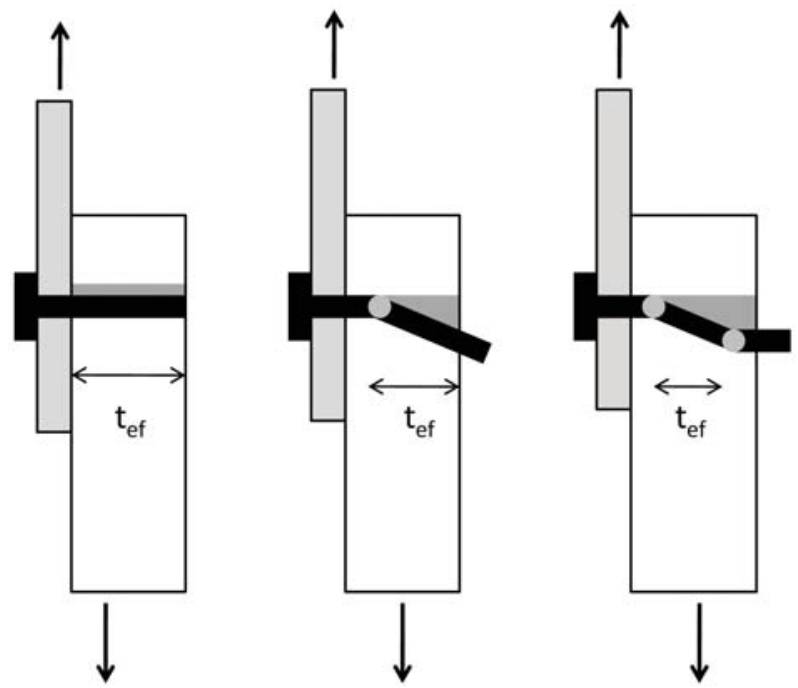

Figure 5: Johansen's predicted ductile modes of failure. 


$$
R_{\text {ductile }}=n^{k_{e f}} F_{v, R}
$$

where

$$
F_{v, R}=\min \begin{cases}f_{h} d t & \text { mode I } \\ f_{h} d t \sqrt{2+\frac{4 M_{y, R}}{f_{h} d t^{2}}-1} & \text { mode II } \\ 2.3 \sqrt{M_{y, R} f_{h} d} & \text { mode III }\end{cases}
$$

\subsection{Minimum spacing, edge and end distances}

In order to address recent critics towards the lack of consideration of brittle modes of failure, the NZS3603 and the EC5 recommend minimum spacing between the fasteners, edge and end distances to minimise the risk of brittle failures according to the nails diameters $d$ (spacing parallel to the grain $a_{1}$, spacing perpendicular to the grain $a_{2}$, distance to the loaded end $a_{3, t^{\prime}}$ distance to the edge $a_{4}$ ).

But these recommendations are not sufficient to fully eliminate the risk of brittle failures to occur in

Table 1: Minimum spacing, edge and end distances recommended by the NZS3603 and the EC5.

\begin{tabular}{|l|c|c|c|c|}
\hline & $a_{1}$ & $a_{2}$ & $a_{3, t}$ & $a_{4}$ \\
\hline NZS3603 $(\mathrm{mm})$ & $10 d$ & $5 d$ & $12 d$ & $5 d$ \\
\hline EC5 $(\mathrm{mm})$ & $10.5 d$ & $5 d$ & $20 d$ & $7 d$ \\
\hline
\end{tabular}

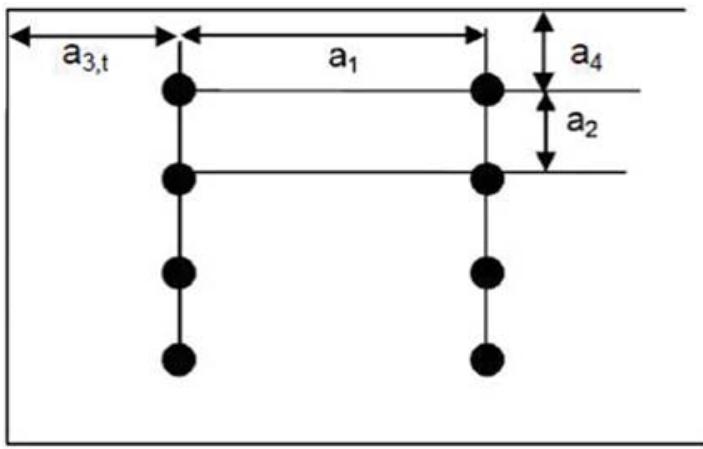

Figure 6: Minimum spacing, edge and end distances recommended by the NZS3603 and the EC5.

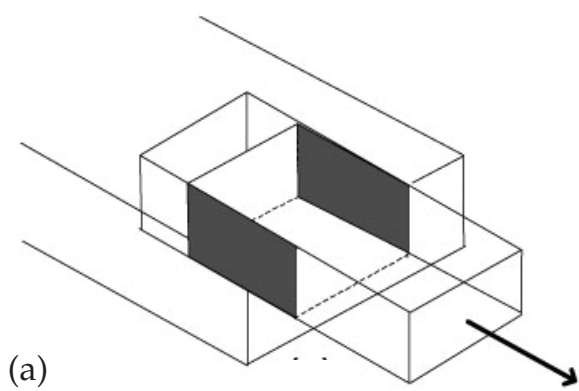

multiple-nail steel-to-timber connections as Johnsson (2004) experienced it with glue-laminated timber.

\section{PREDICTION MODELS FOR BRITTLE FAILURES}

\subsection{Johnsson's equations}

According to Johnsson (2004), the resistance of multiple-nail steel-to-timber connection to plugshear failure $R_{\text {plu }}$ is either due to the tensile resistance of the end face (figure 7(a)) or to the shear resistance of the two side faces (figure $7(b)$ ). It depends on the ratio $p / H$ (the penetration depth of the nail $p$ to the height of the timber member $H$, equations (4) and (5)).

$$
\begin{aligned}
& \text { If } p<\frac{H}{2}, R_{\text {plug }}=\max \left\{\begin{array}{l}
b l f_{v} \\
b p_{e f} f_{t}
\end{array}\right. \\
& \text { If } p>\frac{H}{2}, R_{\text {plug }}=b p_{\text {ef }} f_{t}
\end{aligned}
$$

where $p_{e f}$ is given by the effective thickness of the timber $t_{e f}$ for each mode (figure 5).

During the experiments, the modes of failure were predicted by the lowest of the two capacity resistances of the connection calculated in each mode of failure. In case of ductile modes failures, the loadcarrying capacity of the connection $R_{\text {ductile }}$ was given by the EC5's equations (CEN, 2004). In case of brittle failures, the prediction model of Johnsson (2004) was used to calculate the load-carrying capacity of the connection.

\subsection{Influencing parameters of brittle failures}

The mode of failure of multiple-nail connections depends on three major factors: the timber characteristics, the nails properties and the design of the connection.

Concerning the nails, their ability to deform plastically can be evaluated with the slenderness ratio $\lambda$ defined by the ratio $p / d$ (with $p$ the penetration depth of the nail into the timber member and $d$, the diameter of the nail). Stocky nails, which feature low slenderness ratios (ie. when $d » p$ ), are less prone to deform plastically and tend to lead to brittle failures

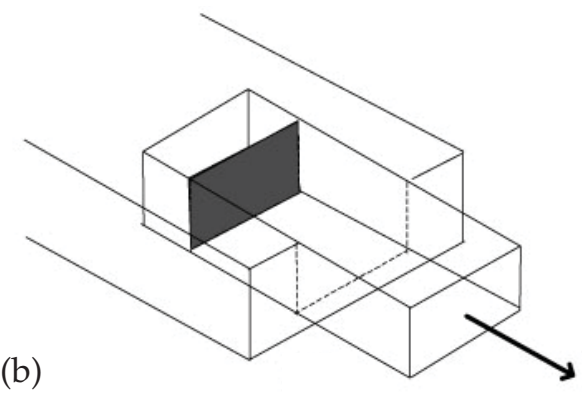

Figure 7: $\quad$ (a) $p / H<1 / 2$, and (b) $p / H>1 / 2$ (Johnsson, 2004). 
while slender nails, with high slenderness ratio (ie. when $d \ll p$ ), would form plastic hinges and promote ductile modes of failure.

The geometry of the connection plays also a significant role on its mode of failure. Small spacing between fasteners lead to a higher risk of brittle failure because fasteners interact more with each other. The stress concentrations around the nails which initiate the crack of brittle failures are indeed more important in case of closer nails. This is why minimum spacing between the fasteners, edge and end distances are recommended in the standards in order to promote ductile modes of failures. According to Johnsson's (2004) experiments, spacing perpendicular the grain is particularly responsible for the formation of brittle failures. Brittle failures would therefore be promoted by small spacing perpendicular to the grain. Experiments lead also to the conclusion that brittle failures are promoted by high number of nails per row, ie. by longer connections.

\section{EMBEDDING STRENGTH PARALLEL TO THE GRAIN}

The NZS3603 lacks many elements concerning the testing, calculation procedures and predicting

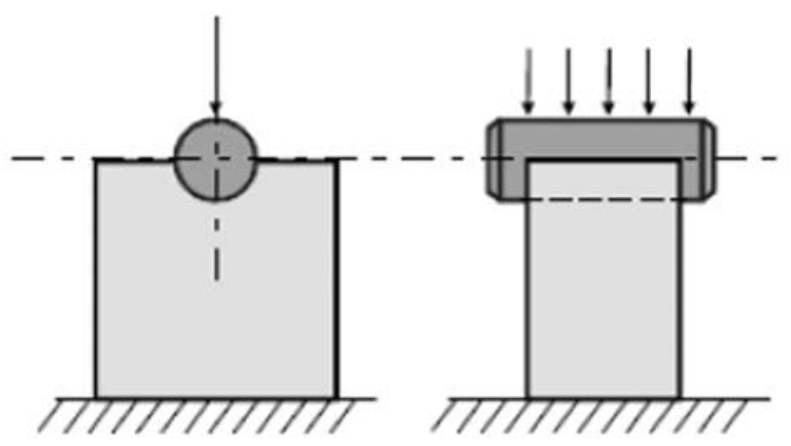

Figure 8: Loading configuration according to the American standard (ASTM, 2005). equations for the embedding strength of New Zealand Radiata Pine solid timber in case of small nail diameters $(d<6 \mathrm{~mm})$. Experiments need to be conducted in order to determine if New Zealand Radiata Pine matches the embedding characteristics established by the EC5 or if new formulas need to be developed. If the obtained results demonstrate a good accuracy with the EC5 equations, these equations will be used later in the load-carrying capacities predicting equations of the tested connections.

\subsection{Testing procedure}

The American half-hole test method (ASTM, 2005) was used in order to avoid any problems concerning potential bending of the nails (figure 8).

The restricted embedment to half the diameter of the nail of the American half-hole test method was highly problematic in the present case of small nail diameters. In order to ensure the reach of the peak load before the loading machine touches the specimen, the following apparatus with a groove acting as the nail was used (figure 9).

The specimens dimensions were $36 \mathrm{~mm}$ in length and in width and featured a varying thickness $t$ depending on the nail diameters in order to achieve a constant slenderness ratio $\lambda=t / d$ of 6 . Four nail diameters $d(2,3.15,4$ and $6 \mathrm{~mm})$ with at least 20 replications were tested. The embedding strength was then determined with the European method using the maximum load reached in the loaddisplacement curve (Zhou \& Guan, 2006).

\subsection{Experimental results}

Table 2 summarises the results obtained for the embedding strength.

Given the coefficient of variation (COV) values around $20 \%$, the results are reliable and accurate with the EC5 equations which predict that characteristic
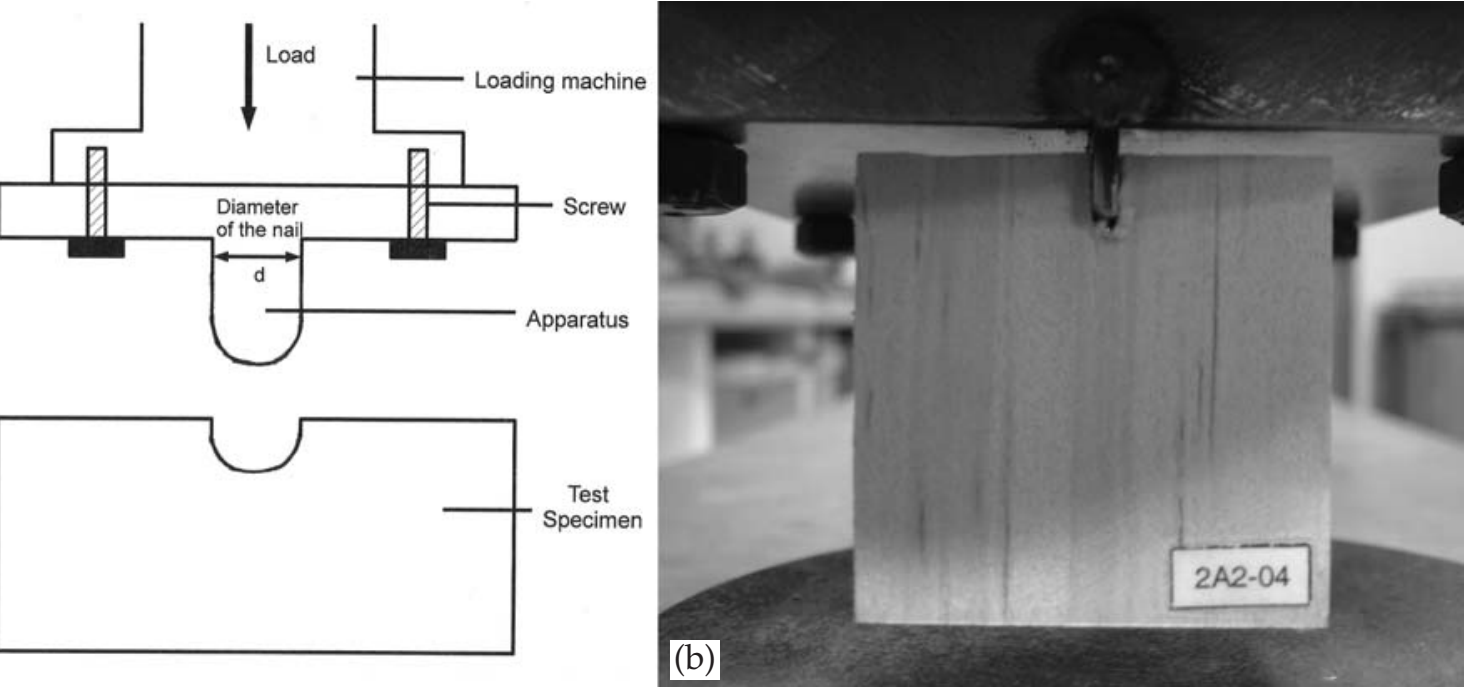

(a)

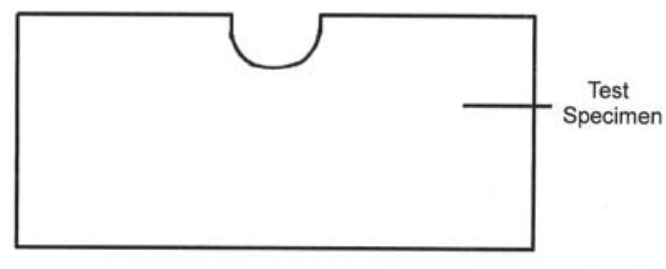

Figure 9: (a) Schematic loading apparatus and (b) realisation in the lab. 
Table 2: $\quad$ Embedding strength results.

\begin{tabular}{|c|l|c|c|c|c|}
\hline \multicolumn{2}{|c|}{} & \multicolumn{4}{|c|}{ Nail diameter $(\mathrm{mm})$} \\
\cline { 3 - 6 } \multicolumn{2}{|c|}{} & 2 & 3.15 & 4 & 6 \\
\hline \multirow{2}{*}{$f_{h, \max }$} & $\begin{array}{l}\text { Mean } \\
\left(\mathrm{kN} / \mathrm{mm}^{2}\right)\end{array}$ & 60.98 & 49.61 & 47.73 & 36.85 \\
\cline { 2 - 6 } & COV $(\%)$ & 20.68 & 22.15 & 23.78 & 17.01 \\
\hline
\end{tabular}

values of embedding strength decrease while the nail diameter increase (equation (6)).

$f_{h, \max }=(0.082-0.00082 d) \rho$

\subsection{Discussion}

The mean values of the experimental results are compared in figure 10 to the EC5 predicted values.

The high coefficient of determination $R^{2}$ shows consistent experimental results in accordance with the linear relationship predicted by the EC 5 between embedding strength and nail diameter. Finally, the EC5's equations are conservative for all tested nail diameters and can be safely used to predict the embedding strength of small nail diameters for New Zealand Radiata Pine solid timber.

However, the use of the maximum load to calculate the embedding strength has been controversial because it would overestimate the resistance of wood to embedding by $20 \%$ (Bléron, 2000). But in case of small nail diameters for New Zealand Radiata Pine solid timber, the use of the American 5\% offset method - based on the intersection load between the load-displacement curve and an offset line at $5 \%$ of fastener diameter - gives similar results. The general tendency of the EC5's equations is to be more conservative than the experimental results (figure 11).
5

\section{EXPERIMENTAL PROCEDURE}

The investigation on the modes of failure of multiplenail steel-to-timber connections was lead according to the recommendations made by the EC5 and NZS3603 standards used by the industrials in timber design. In this way, the results would be directly relevant to the engineers.

\subsection{Design of the steel plates}

The aim of the experiments was to determine if the risk of brittle failures is significant in case of multiplenail steel-to-timber connections made with New Zealand Radiata Pine solid timber. That is why small spacing especially perpendicular to the grain and high number of nails per row were chosen in order to maximise the risk of brittle modes of failure. The nails patterns of the steel plates are described with the geometric parameters used in the EC5. Four groups of connections with nails of $3.33 \mathrm{~mm}$ diameters have been tested. The first group, Group 1, comprised eight replications and the following three groups, Groups 2 to 4 , comprised six replications for a grand total of 26 tested specimens. Groups 1 and 2 featured the smallest spacings recommended by the EC5. In Groups 3 and 4, spacing perpendicular to the grain $a_{2}$ was reduced by 2 in order to test the influence of reduced spacing perpendicular to the grain on brittle modes of failure (figure 12). The number of nails per row $n$ and of rows parallel to the grain $m$ were determined according to calculations made on the predicted load-carrying capacities of the connections which are explained later in the text.

\subsection{Experimental set-up}

Multiple-nail steel-to-timber connections made with New Zealand Radiata Pine solid timber were tested

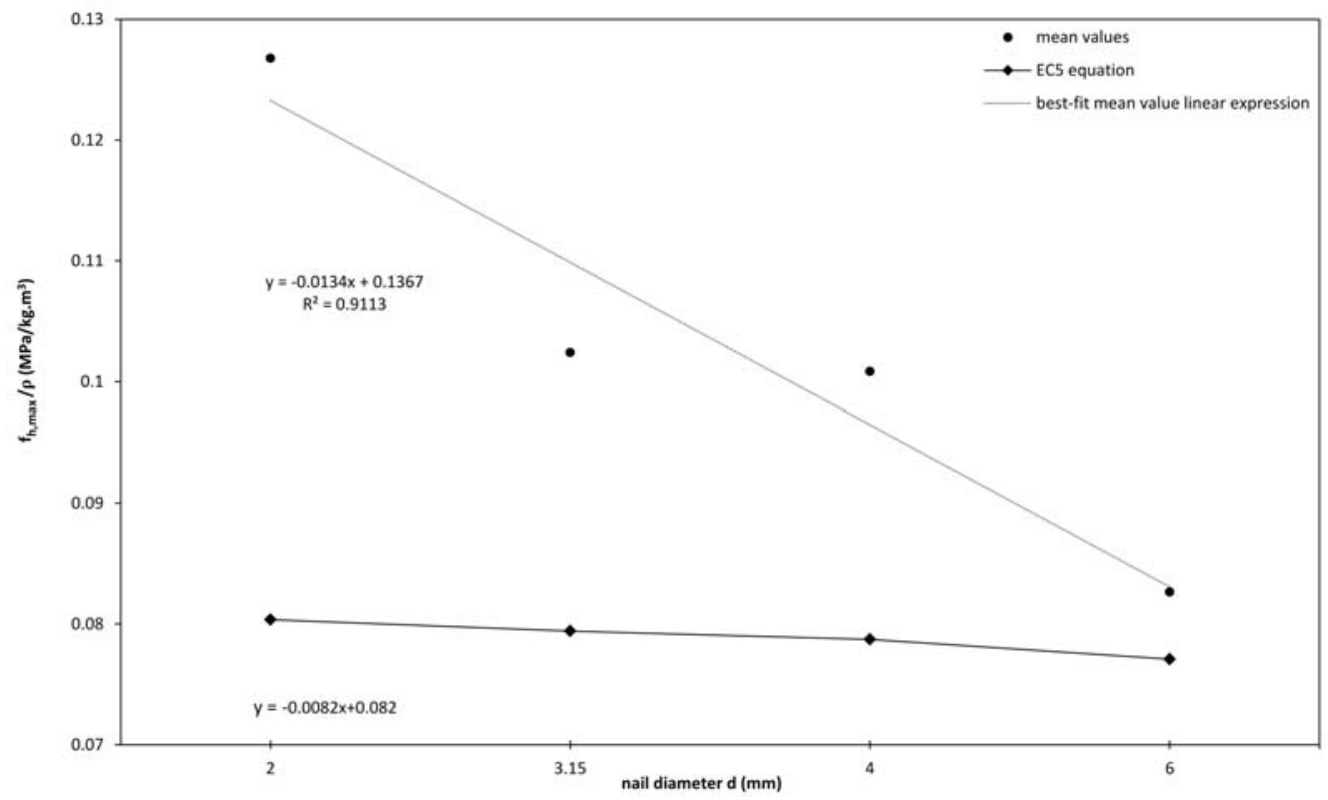

Figure 10: Comparison of $f_{h, \text { max }}$ experimental results to the EC5. 


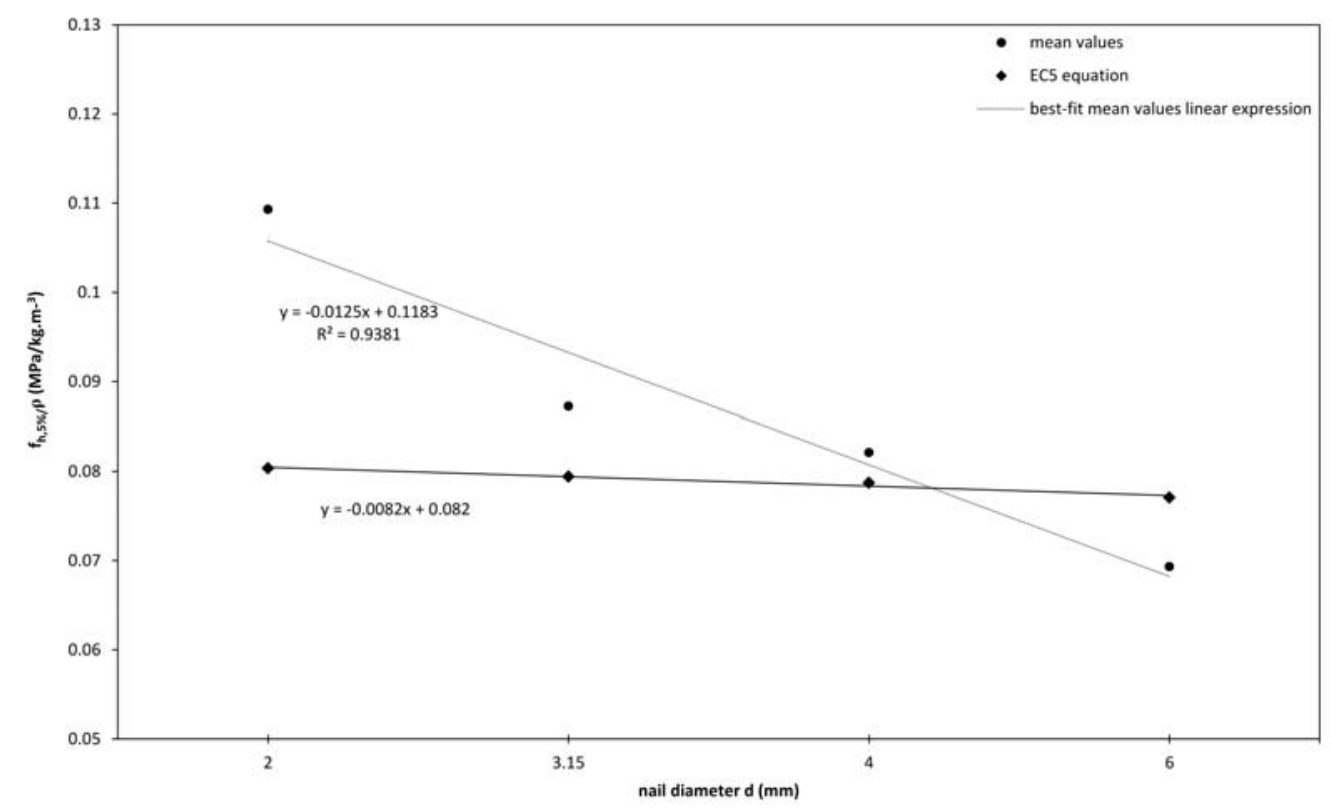

Figure 11: Comparison of $f_{h, 5 \% \text { offset }}$ experimental results to the EC5.

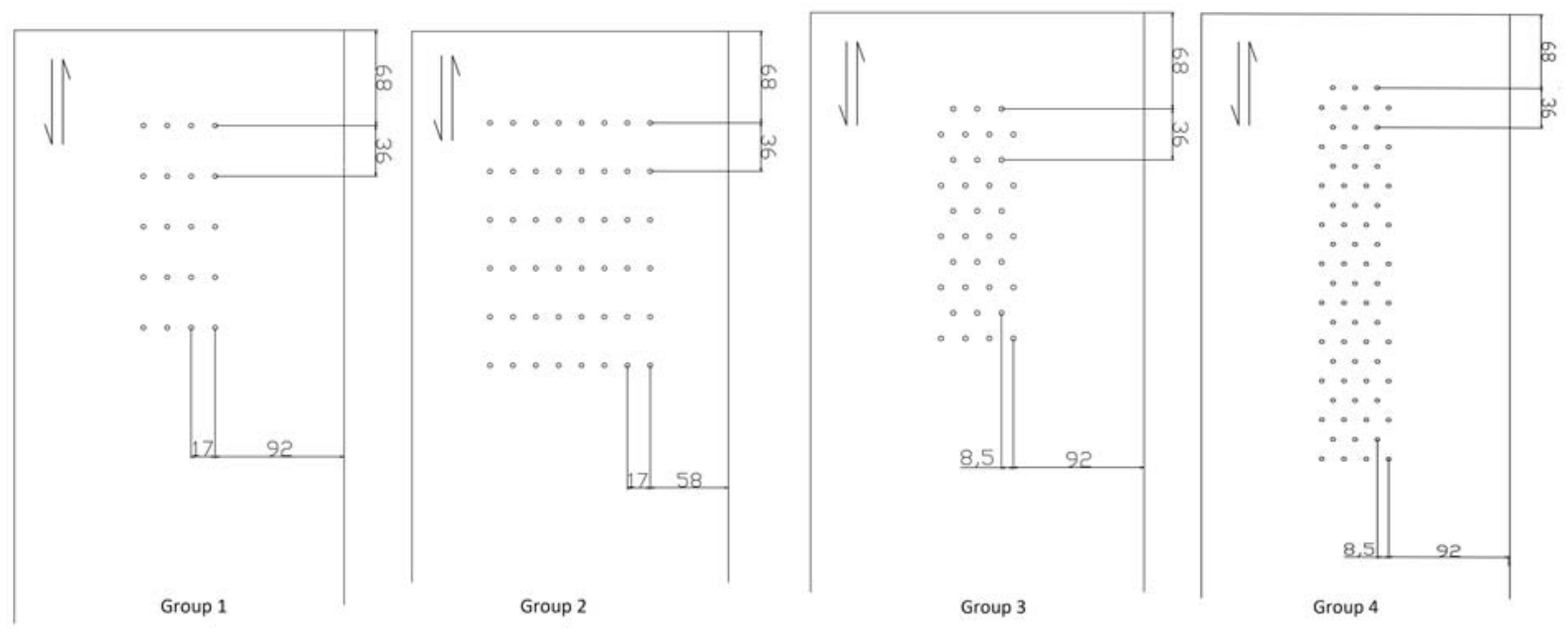

Figure 12: Nailing patterns of the tested groups represented in the timber member.

Table 3: Geometric parameters of the tested groups.

\begin{tabular}{|l|c|c|c|c|c|c|c|}
\hline & $m(\mathrm{~mm})$ & $n(\mathrm{~mm})$ & $b(\mathrm{~mm})$ & $a_{1}(\mathrm{~mm})$ & $a_{2}(\mathrm{~mm})$ & $a_{3, t}(\mathrm{~mm})$ & $a_{4}(\mathrm{~mm})$ \\
\hline EC5 & & $10.5 d$ & $5 d$ & $20 d$ & $7 d$ \\
\hline Case of $d=3.33$ & & 36 & 17 & 68 & 24 \\
\hline Group 1 & 4 & 5 & 54 & 36 & 17 & 68 & 92 \\
\hline Group 2 & 8 & 6 & 122 & 36 & 17 & 68 & 58 \\
\hline Group 3 & 7 & 5 & 54 & 36 & 8.5 & 68 & 92 \\
\hline Group 4 & 7 & 10 & 54 & 36 & 8.5 & 68 & 92 \\
\hline
\end{tabular}

in tension parallel to the grain. Four multiple-nail connections were involved per test: the timber member was connected on both ends to obtain the most accurate results and integrate the probability of the weakest end to fail first (figure 13(a)) and on both sides to avoid problems of eccentricity (Figure 13b). The load was applied to one end of the timber member while the other end remained fixed to the floor. The loading procedure followed the recommendations of the ISO 6891 Standard (ISO, 1983). Portal gages recorded the load-displacement curves for each side of the tested specimen.

The timber members were cut from New Zealand Radiata Pine solid timber graded VSG 8. They 

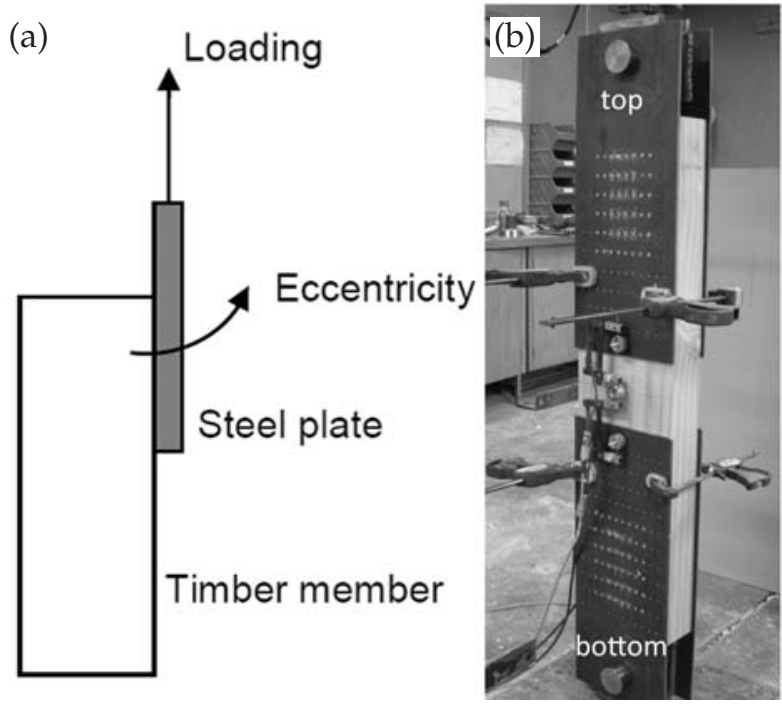

Figure 13: (a) Experimental set-up and

(b) problems of eccentricity.

Table 4: $\quad$ Measured timber characteristics.

\begin{tabular}{|l|c|c|c|}
\hline & $E(\mathrm{GPa})$ & $\rho\left(\mathrm{kg} / \mathrm{m}^{3}\right)$ & $M C(\%)$ \\
\hline Group 1 & 8.1 & 488.08 & 16.5 \\
\hline Group 2 & 9.1 & 504.90 & 15.4 \\
\hline Group 3 & 8.0 & 509.12 & 15.7 \\
\hline Group 4 & 8.1 & 488.27 & 16.2 \\
\hline
\end{tabular}

feature high-density mean values $\left(\rho>475 \mathrm{~kg} / \mathrm{m}^{3}\right)$. Their modulus of elasticity $E$ measured with the velocity of the sound in timber (Haines et al, 1996) meet the requirements of VSG 8 grade according to the New Zealand Standard NZS3603. Thus, the characteristic tensile strength $f_{t, k}=6 \mathrm{MPa}$ given by NZS3603 was considered as an accurate value used in the calculations to evaluate the strength of the tested timber.

Steel plates had a thickness $c=6 \mathrm{~mm}$ and a standard yield strength value $f_{y}=250 \mathrm{MPa}$. The steel plates were predrilled manually at the workshop with holes appropriate to the nails diameter.

Nails had a diameter $d=3.33 \mathrm{~mm}$ and were $38 \mathrm{~mm}$ long so that the penetration depth of the nails $p$ given by $p=l_{\text {nail }}-c=32 \mathrm{~mm}$ (figure 14).

The measure of the tensile strength of the wire $f_{u}$ reveals that the steel used to manufacture the nails was of very high strength $\left(f_{u}=1464.0 \mathrm{MPa}\right)$. But it did not experience any ductile deformation during the tests: the failure was sudden and brittle with no elongation of the steel. To comply with the method in use on construction sites, nails were not predrilled but driven directly into the timber member through the holes of the steel plates with a compressed air nail gun.

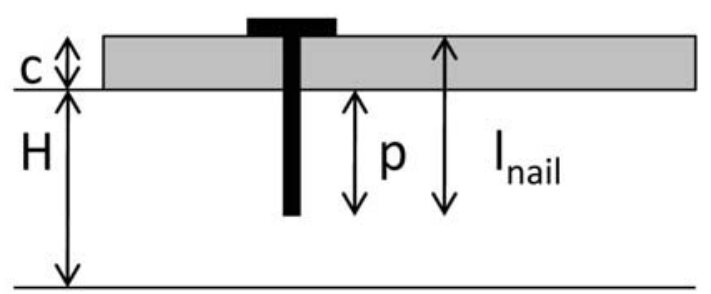

Figure 14: Penetration depth of the nails $p$ in the timber member.

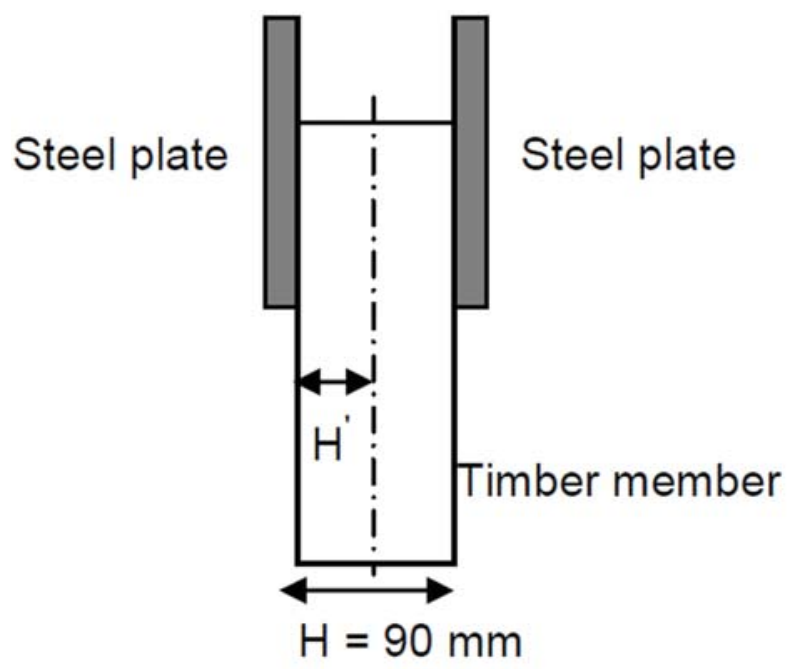

Figure 15: "Apparent" height of timber $H^{\prime}$ per connection.

6

\section{EXPERIMENTAL PREDICTIONS}

\subsection{Calculations for ductile failures}

The capacity resistance of the connection in case of ductile failure $R_{\text {ductile }}$ is given by equation (2) where:

- $k_{\text {ef }}=0.87$ (extrapolation to the case of $a_{1}=10.5 \mathrm{~d}$ of the value recommended by the EC5 (CEN, 2004, Table 8.1.))

- $f_{h}=0.082 \rho d^{-0.3}=0.082 \times 470.10 \times 3.33^{-0.3}=26.8 \mathrm{MPa}$ (CEN, 2004, Section 8.3.1.1.)

- $M_{y, R}=0.3 f_{u} d^{2.6}=0.3 \times 1464.0 \times 3.33^{2.6}=10023 \mathrm{Nmm}$ (CEN, 2004, Section 8.3.1.1.).

\subsection{Calculations for brittle failures}

For each connection, the "apparent" cross-sectional height of the timber is $H^{\prime}=90 / 2=45 \mathrm{~mm}$ (figure 15). Therefore, the ratio $p / H^{\prime}=32 / 45=0.7>1 / 2$ so that according to Johnsson (2004), only the tensile strength of the end face will play a role in the resistance of the connection in case of brittle failure.

The load-carrying capacity of the connection in case of the brittle failure is given by equation (4) where $b$ is the width of the connection is given in table 3, $f_{t}=6 \mathrm{MPa}$ (Standards New Zealand, 1993, Table 2.3), and $p_{e f}=2 \sqrt{\frac{M_{y}}{f_{h} d}}=2 \sqrt{\frac{10,023}{26.8 \times 3.33}}=106 \mathrm{~mm}$. 
Due to the high value of the nail yield moment $M_{y}$ induced by the high tensile strength of the wire $f_{u^{\prime}} p_{e f}$ exceeds the penetration depth of the nail $p=32 \mathrm{~mm}$. This has no physical sense. It was therefore decided to take $p_{e f}=p=32 \mathrm{~mm}$. This choice will be discussed later in the text.

\subsection{Choices of experiments}

The behaviour of the multiple-nail steel-to-timber connection was predicted according to the smallest of the two capacity resistances of the connection calculated in each mode of failure. If $R_{\text {ductile }} / R_{\text {plug }}<1$, the mode of failure would be predicted as ductile; if $R_{\text {ductile }} / R_{\text {plug }}>1$, the mode of failure would be predicted as brittle. The aim of the experiments was to achieve brittle mode of failure. Therefore, the tested nails patterns were chosen among the configurations which lead to ratios $R_{\text {ductile }} / R_{\text {plus }}>1$ (figure 16).

\section{EXPERIMENTAL RESULTS}

\subsection{Failure loads}

Figure 17 features one of the load-displacement graphs obtained during the experiments. The

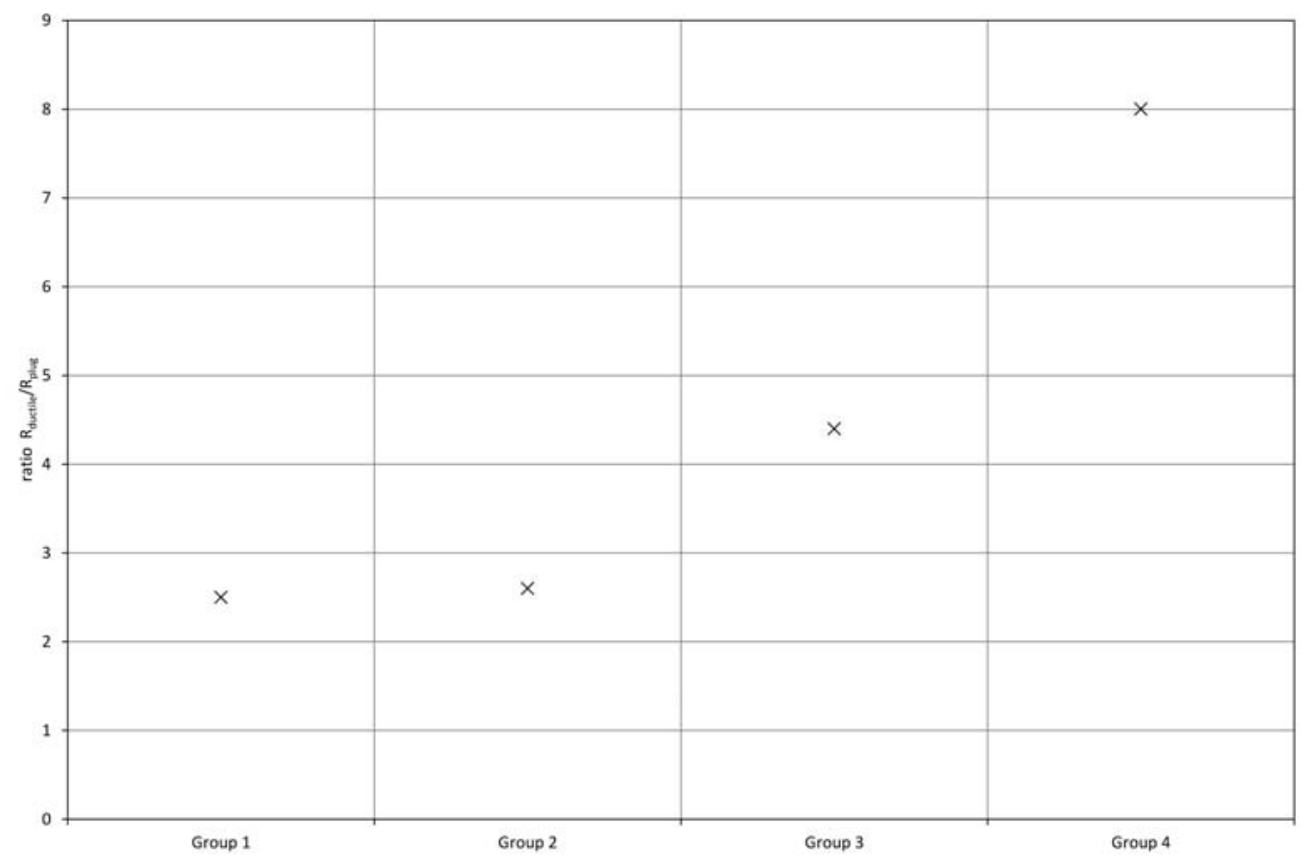

Figure 16: Calculated ratios of $R_{\text {ductile }} / R_{\text {plug }}$ for each tested group.

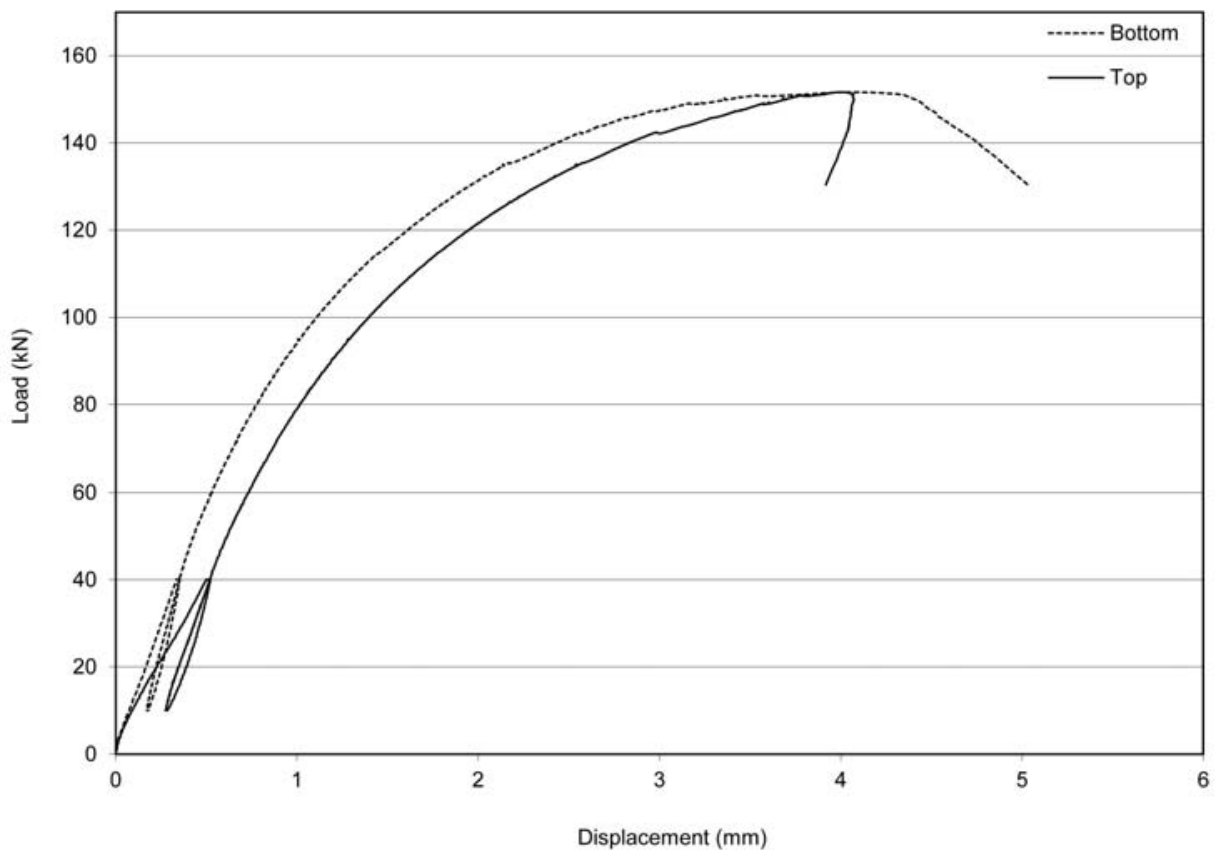

Figure 17: Load-displacement graphs of one specimen of Group 3. 
Table 5:

Test results.

\begin{tabular}{|c|c|c|c|c|}
\hline \multicolumn{2}{|c|}{ Test specimen } & Max. load per steel plate (kN) & Failure mode & Failure end \\
\hline \multirow{11}{*}{ Group 1} & $1-45-1$ & 29.0 & ductile & bottom \\
\hline & $1-45-2$ & 29.1 & ductile & bottom \\
\hline & $1-45-3$ & 32.9 & ductile & bottom \\
\hline & $1-45-4$ & 33.4 & ductile & bottom \\
\hline & $1-45-5$ & 25.9 & ductile & bottom \\
\hline & $1-45-6$ & 23.6 & ductile & bottom \\
\hline & $1-45-7$ & 25.9 & ductile & top \\
\hline & $1-45-8$ & 27.0 & ductile & top \\
\hline & Average & 28.4 & & \\
\hline & Std dev. & 3.2 & & \\
\hline & $\operatorname{COV}(\%)$ & 11.4 & & \\
\hline \multirow{9}{*}{ Group 2} & $2-86-1$ & 52.4 & ductile & top \\
\hline & $2-86-2$ & 65.9 & ductile & top \\
\hline & $2-86-3$ & 76.2 & ductile & top \\
\hline & $2-86-4$ & 75.2 & ductile & top \\
\hline & $2-86-5$ & 68.4 & ductile & bottom \\
\hline & $2-86-6$ & 81.1 & ductile & bottom \\
\hline & Average & 69.8 & & \\
\hline & Std dev. & 9.3 & & \\
\hline & COV (\%) & 13.3 & & \\
\hline \multirow{9}{*}{ Group 3} & 3-75red-1 & 37.7 & ductile & top \\
\hline & 3-75red-2 & 38.6 & ductile & top \\
\hline & 3-75red-3 & 51.0 & ductile & top \\
\hline & 3-75red-4 & 46.6 & ductile & bottom \\
\hline & 3-75red-5 & 47.9 & ductile & top \\
\hline & 3-75red-6 & 47.9 & ductile & bottom \\
\hline & Average & 45.0 & & \\
\hline & Std dev. & 5.0 & & \\
\hline & $\operatorname{COV}(\%)$ & 11.1 & & \\
\hline \multirow{9}{*}{ Group 4} & 4-710red-1 & 106.6 & ductile & bottom \\
\hline & 4-710red-2 & 105.7 & ductile & top \\
\hline & 4-710red-3 & 85.0 & ductile & bottom \\
\hline & 4-710red-4 & 113.6 & ductile & top \\
\hline & 4-710red-5 & 96.4 & ductile & bottom \\
\hline & 4-710red-6 & 107.1 & ductile & bottom \\
\hline & Average & 102.4 & & \\
\hline & Std dev. & 9.3 & & \\
\hline & COV (\%) & 9.0 & & \\
\hline
\end{tabular}


Table 6: Load-carrying capacity of the nails used in the experiments.

\begin{tabular}{|l|c|c|c|}
\hline & $\begin{array}{c}\text { Max. load } \\
\text { per steel } \\
\text { plate (kN) }\end{array}$ & $\begin{array}{c}\text { No. of } \\
\text { nails per } \\
\text { steel plate }\end{array}$ & kN/nail \\
\hline Group 1 & 28.3 & 20 & 1.4 \\
\hline Group 2 & 66.4 & 48 & 1.4 \\
\hline Group 3 & 45.0 & 32 & 1.4 \\
\hline Group 4 & 102.4 & 67 & 1.5 \\
\hline & & Average & 1.4 \\
\hline
\end{tabular}

curve titled "Bottom" (resp. top) represents the displacement of the steel plates located at the bottom of the timber member (resp. at the top) (figure 13).

The calculations of the load-carrying capacities of the nails gave consistent results which account for the accuracy of the obtained values for the maximum loads at failure (table 6). For the each tested group, in average, each nail was able to carry a load of $1.4 \mathrm{kN}$.

The plotted load-displacement graphs gave similar results for all groups. All tested connections featured a ductile behaviour and showed a plastic deformation before the failure of one end which happened randomly either at the top or at the bottom end (table 5).

\subsection{Failure behaviour}

This ductile behaviour was confirmed by the observation of the specimens once tested. The removal of the steel plates showed that the nails have started to bend by forming one plastic hinge (figure 18(a)). The embedment of the nails into the timber for a distance of 3 to $5 \mathrm{~mm}$ could also be noticed (figure 18(b)). During the experiments, the noise of some nails breaking could also be heard. The rupturing of the nails happened at random and no particular location of the nails rupturing could be noticed on the nailing patterns. The connection weakened by the loss of those missing nails finally yielded when one steel plate lifted out of the timber member.

\section{DISCUSSIONS}

\subsection{Ductile failure loads}

As no brittle failure was obtained during the experiments, it is not possible to check the accuracy of Johnsson's (2004) predicting equations for plugshear failure. However, it is still interesting to check the conformity of the obtained ductile results with the EC5's predicting equations. The percentage
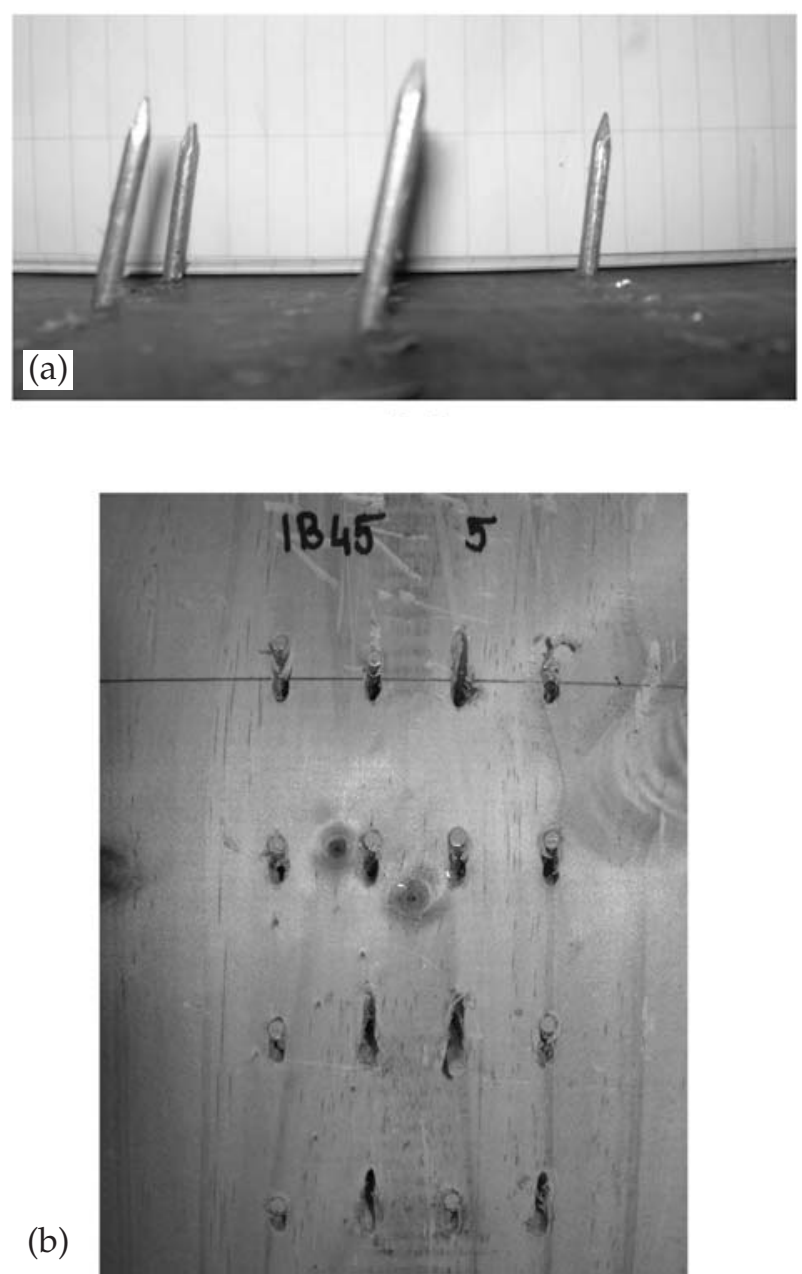

Figure 18: (a) Nails starting to bend and (b) embedment of the nails into the timber (not at scale).

difference in experimental results and predicted failure loads have been calculated with equation (7), below.

Results account for negligible percentages of difference experimental results and predicted failure loads for Groups 1 and 2 when minimum spacing respect the recommendations of the EC5 (figure 19). On the other hand, the significant percentage difference obtained for Groups 3 and 4 (respectively $11 \%$ and $14 \%$ ) may due to the fact that Groups 3 and 4 featured smaller minimum spacing than those recommended by the EC5.

To reduce the spacing increases the number of fibres which are more concentrated between the nails. The density of timber is locally higher like its embedding strength because these two values are linearily linked (CEN, 2004, Section 8.3.1.1). This may explain why the EC5 equations based on the embedding strength are not so accurate in case of reduced spacing.

$$
\% \text { difference }=100 \frac{\text { experimental result }- \text { predicted failure load }}{\text { predicted failure load }}
$$




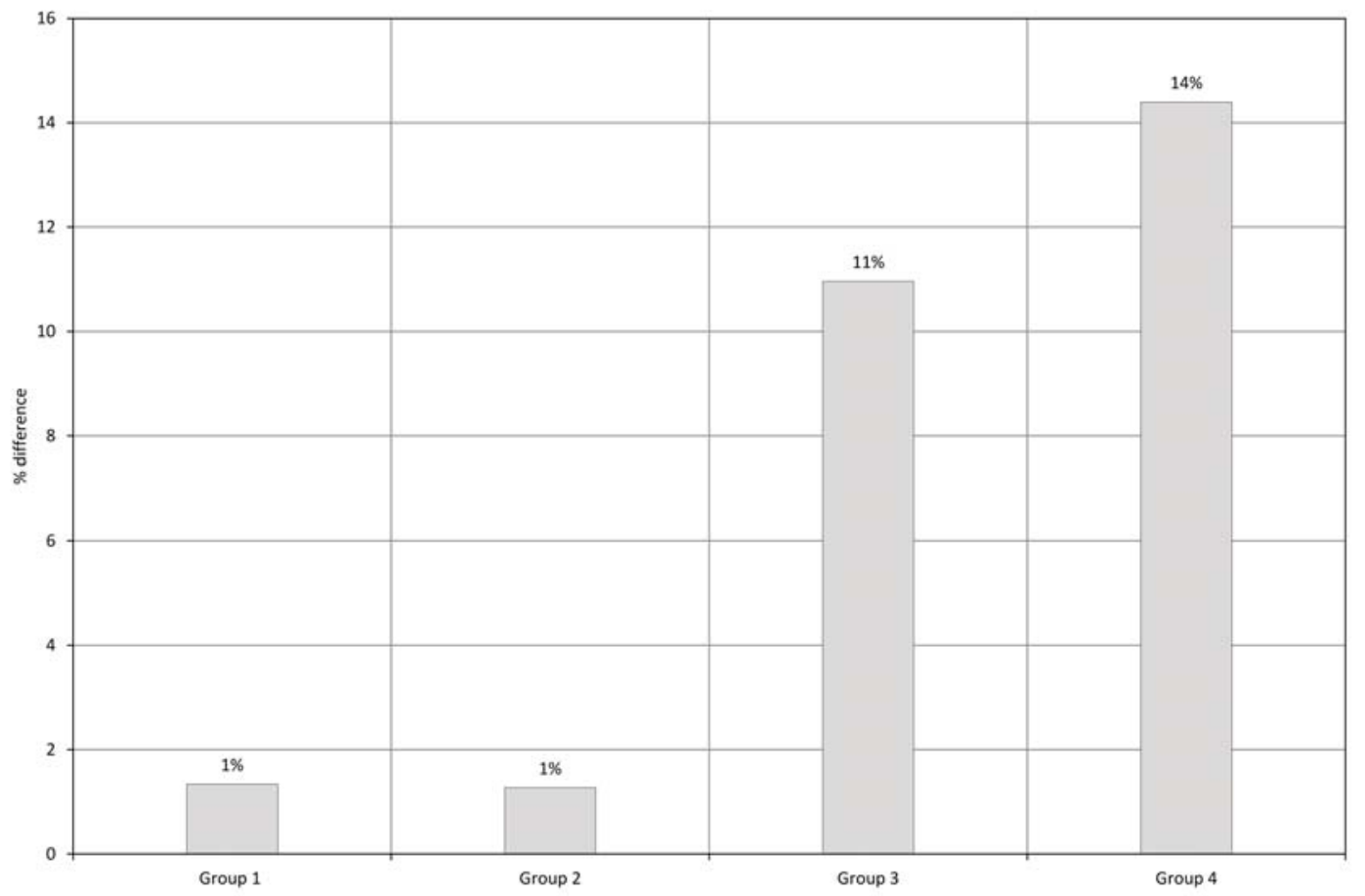

Figure 19: Plot of expected versus experimental ductile failure loads per steel plate.

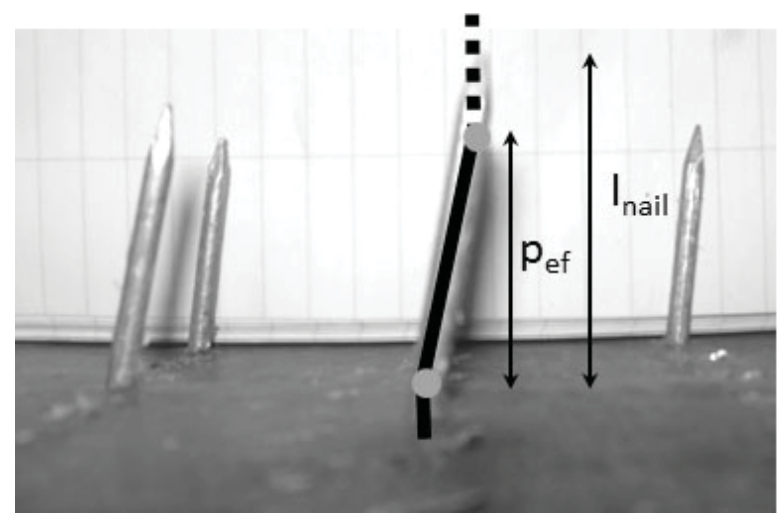

Figure 20: Mode II failure observed on nails.

\subsection{Ductile failure behaviour}

The predicted mode of failure according to the EC5's equations was the same for all the tested groups: the mode II where the nails would yield in forming one plastic hinges (equation (2)). Visually during the experiments, the nails have started to bend at the junction of the steel plate and the timber member. The formation of the first plastic hinge can be observed. Longer nails may have clearly shown a ductile failure in mode III and confirmed the predictions of the EC5 as did the experimental obtained values of maximum loads at failure (figure 20).

\section{CONCLUSIONS}

Johnsson's (2004) equations fail to predict the right mode of failure in case of multiple-nail connections made with New Zealand Radiata Pine. Ductile failures occurred where her equations predicted brittle failures. As no brittle failure was obtained during the experiments, it is not possible to verify the reliability of Johnsson's (2004) equations to predict the maximum loads at failure in case of brittle mode of failure. But these experiments demonstrate that New Zealand Radiata Pine solid timber is more prone to fail in a ductile mode than glue-laminated timber even when the risk of brittle failure is emphasised by "reduced" spacing perpendicular to the grain. Therefore, brittle failures in multiple-nail steel-totimber connections loaded parallel to the grain made with New Zealand Radiata Pine solid timber do not constitute a risk of high probability. An additional conclusion drawn from the experiments is the reliable accuracy of the predicting load-carrying capacities of the EC5 for multiple-nail steel-to-timber connections made with New Zealand Radiata Pine solid timber when minimum recommended spacing are respected.

\section{ACKNOWLEDGEMENTS}

The authors wish to thank the technical staff of the University of Auckland Timber Laboratory for their help in conducting the experiments and to express their gratitude to the STIC Program for supporting this project.

\section{REFERENCES}

American Society for Testing and Materials (ASTM), 2005, ASTM D5764-97a Standard Test Method for Evaluating Dowel-Bearing Strength of Wood and WoodBased Products. 
Bléron, L. 2000, Contribution à l'optimisation des performances d'assemblages bois en structure: Analyse de la portance dans les assemblages de type tige, UHP Nancy 1.

Comité Européen de Normalisation (CEN), 2004, EN 1995-1-1 Eurocode 5: Design of timber structures Part 1.1: General rules and rules for buildings, Brussels, Belgium.

Haines, D. W., Leban, J. M. \& Herbé, C. 1996, "Determination of Young's modulus for spruce, fir and isotropic materials by the resonance flexure method with comparisons to static flexure and other dynamic methods", Wood science and technology, Vol. 30, No. 4, pp. 253-263.

International Standards Organisation (ISO), 1983, ISO 6891 - Timber Structures - Connections made with mechanical fasteners - General principles and determination of strength and deformation characteristics.

Johansen, K. W. 1949, "Theory of timber connections", International Association of Bridge and Structural
Engineering (IABSE), Bern, Switzerland, Vol. 9, pp. 249-262.

Johnsson, H. 2004, "Plug shear failure in nailed timber connections: avoiding brittle and promoting ductile failures", PhD thesis, Luleå University of Technology, Luleå, Sweden.

Madsen, B. 2001, "Behaviour of timber connections", Canadian Journal of Civil Engineering.

Quenneville, P. \& Morris, H. 2009, “Proposal for a mechanics-based bolted connection design approach for AS1720.1", Australian Journal of Structural Engineering, Vol. 9, No. 3, pp. 195-205.

Standards New Zealand, 1993, NZS3603 - Timber Structures Standard, New Zealand Timber Design Code.

Zhou, T. \& Guan Z. 2006, "Review of existing and newly developed approaches to obtain timber embedding strength", Progress in Structural Engineering and Materials, Vol. 8, No. 2, pp. 49-67. 